\title{
Evaluation of JianKang Health Club's Business Model Research
}

\author{
Xinyi $\mathrm{Li}^{1, *}$ \\ ${ }^{1}$ University of California Santa Barbara \\ *Corresponding author.Email: xinyi_li@ucsb.edu
}

\begin{abstract}
Under the current fitness industry, customers pay a high price to hire personal trainers, while personal trainers receive limited and unsatisfactory salaries. This article proposes and analyses a new business model to replace the current unreasonable business model in the fitness industry. Customers pay less on hiring trainers, and personal trainers earn more. The JianKang Health Club is conducted by building a platform where customers contact personal trainers directly without the middleman receiving money. Also, besides the main function, this platform contains other functions, including sharing photos and videos on the personal page, recording unpaid and paid classes, etc. Customers choose where to take training classes to avoid wasting time on the commuter journey, and they pay an affordable price to hire personal trainers to help them exercise better. Personal trainers gain more spare time to develop other jobs besides teaching since they do not need to stay in the office all day, and their salary increases because they gain what customers pay. Furthermore, this article discusses the promising profits of running this platform. Several potential ways to ensure the profits, including receiving membership fees, putting advertisements on the platform, etc. Moreover, this article analyses the number of customers who will be attracted to this platform. Not only does this research contribute to the reformation of the current fitness industry to satisfy both customers' and trainers' needs, but also it promotes more creative thoughts about how to adjust a field's business model to serve customers better.
\end{abstract}

Keywords: The fitness centers, Exercising, Business Model

\section{INTRODUCTION}

According to new research, the market size of the global fitness and health club industry has been steadily increasing in recent years, exceeding 96 billion U.S. dollars in 2019 [1]. The number of people who pay attention to their health and associate their health condition with exercising increases rapidly, especially after experiencing trauma brought by the COVID-19 pandemic. However, the economic growth is negatively impacted by the COVID-19 pandemic. More and more people do not have enough money to pay expensive gym membership fees and hire trainers. For example, "the total employment income at EU level decreased by $-4.8 \%$ in 2020, with the largest decreases due to absences and reduced hours" [2]. Many people lose their jobs, and some of them even have to pay expensive treatment fees to heal from the disease. Therefore, a new business model is urgent to help people hire trainers using less money to work out correctly.
Due to developed digitalization, almost every business has to adapt to the change and improve its operation to satisfy customers' needs. The fitness industry is also the case. In the past, customers and trainers have to meet face to face in gyms to schedule classes, and bosses of gyms make money out of providing them ways to meet each other and giving them places to take classes. The average commission that a personal trainer working in a commercial gym may earn is typically between $30 \%$ and $60 \%$, depending on their education, experience and certificate [3]. Fortunately, the face-to-face business model can be updated now. Our platform, which takes advantage of global digitalization, allows customers and trainers to communicate online to save time and money. They do not have to be restricted to gyms, and they do not have to pay gyms extra fees for introducing them to each other. As they get personal training experience, try to stick to 25-30 hours a week (max) for actual training sessions. They'll need non-training time for scheduling, invoicing, working out, promoting your business on social media, and more [4]. When our platform has been successfully carried out, more people who want to work 
out in the right way but cannot pay expensive personal trainers' fees will be satisfied by finding cheap trainers on our platform, and more trainers who do not want to waste the whole day in gyms and do not want to share classes' fees with the gyms will be satisfied by contacting customers directly through our platform.

The goal is to build a platform that matches personal trainers with customers and uses this new model to replace the traditional fitness industry. Personal trainers do not have to stay in the office the whole day, so that they have more spare time to do their own business, such as building their muscles, making friends, or doing part time jobs. In this way, they can control their time more than the days they work in the traditional fitness industry. In addition, they can earn more because we only take ten per cent of what customers pay. Traditional fitness center usually takes more than thirty per cent of what customers pay. Also, they can have the second or third jobs since we do not ask any personal trainer to stay in the office all day.

For customers, they can have more flexibility to decide where to exercise, but they also pay less to enjoy personal classes with the same quality. In the past, customers had no choice but to drive to the fitness center to exercise, usually taking ten to thirty minutes on the road. They had to pay the high price, which usually cost three hundred to seven hundred for an hour to hire personal trainers. People who cannot afford personal trainers have to exercise by themselves. Unfortunately, they are often harmed by incorrect gestures and unhealthy methods because they lack professional instructions on exercising and stretching the muscle. When our products come out, customers can find suitable personal trainers on our platform and find convenient locations for them, such as a vacant room in their workplace, open sports grounds, or even at home. They can hire personal trainers at a low cost, usually one to three hundred depending on customers' expectations and classes' difficulties. This price is affordable to most of our target customers.

We take ten per cent of what customers pay, which is far less than what traditional fitness centers take, and we use part of this money for better regulation. We hire staff to supervise users and punish customers or personal trainers if they break the rules. For example, suppose customers misbehave during classes, including being late for more than ten minutes, being rude to personal trainers, being inactive during classes, and so on. In that case, we will ask them to pay extra tips to personal trainers and give them low scores on the rating system. If personal trainers show misbehaviours, we will ask them to return ten per cent of the class fee to customers and give them low scores on the rating system.

Another way to persistently run this platform is that we accept advertisements. For example, if brands related to sports, such as energy milkshakes, running shoes, watches to detect a heartbeat, and so on, want to put advertisements on our platform, we charge the amount of fee to advertise for them on our platform. Many brands produce high quality goods and sell them at a low price, but sales volume is not ideal because they are new to the market, so many of them will be willing to spend money on letting more people know their brands through our platform. Also, advertising those brands to our users can help us attract more people to join our platform. By looking at the platform's advertisement, they can know brands that sell reasonably, invent new technology for products, or design fashionable looks for new products. When we put the advertisement on the platform, there will be a link in it. Users can click the link to buy the products, and the number of items sold will be calculated back site. Also, we charge the companies extra money by multiplying the number of items sold, single product's price, and 0.01 .

Another function of our platform is that personal trainers can record classes about how to exercise, sketch, and so on, and put recorded videos on their personal pages. Then, they decide videos' price, which is around ten to one hundred. Also, they can put free videos to increase their popularity and attract more customers. Customers gain knowledge about building in shape, losing weight, heal arm illness, and so on by watching these videos. This function attracts more customers to our platform, help personal trainers earn an extra salary, and allow users to learn professional knowledge at home whenever they have time.

This research article will analyze the current fitness industry based on data reports and people's judgments. Also, we discuss potential customers who will be attracted to our new business model based on the current global economy and people's behaviors. More, we elaborate risks and profits by carrying out our business model in the fitness industry.

\section{DATA}

\subsection{Data resources}

The form of the traditional fitness industry is that customers pay membership fees and pay for hiring personal trainers if they want more professional Instructions. In recent one hundred years, many gyms have been opened all over the world. Take the United States as an example, "Since the 1960s, the nature of recreational physical fitness activity in the United States has changed considerably. By 2000, private fitness centers were ubiquitous features on the American landscape" [5]. A 2020 report on the global gym industry estimates there are a total of 205,176 gyms in the world. An increase of $12.11 \%$ from the 183,000 gyms available worldwide in 2014 [6]. The figure below shows the top 10 countries with the most members per gym in 2014 . We can see the number of people who go to gyms is quite large all over the world. Gyms make money out of 
receiving membership fees and draw a large percentage out of trainers' gains. For example, the average annual membership cost is $\$ 507$ for the first year in the US. The cost drops to $\$ 479$ for the succeeding years because you no longer pay any initiation or enrolment fees [6]. Nowadays, gyms are still the major trend in the fitness industry.

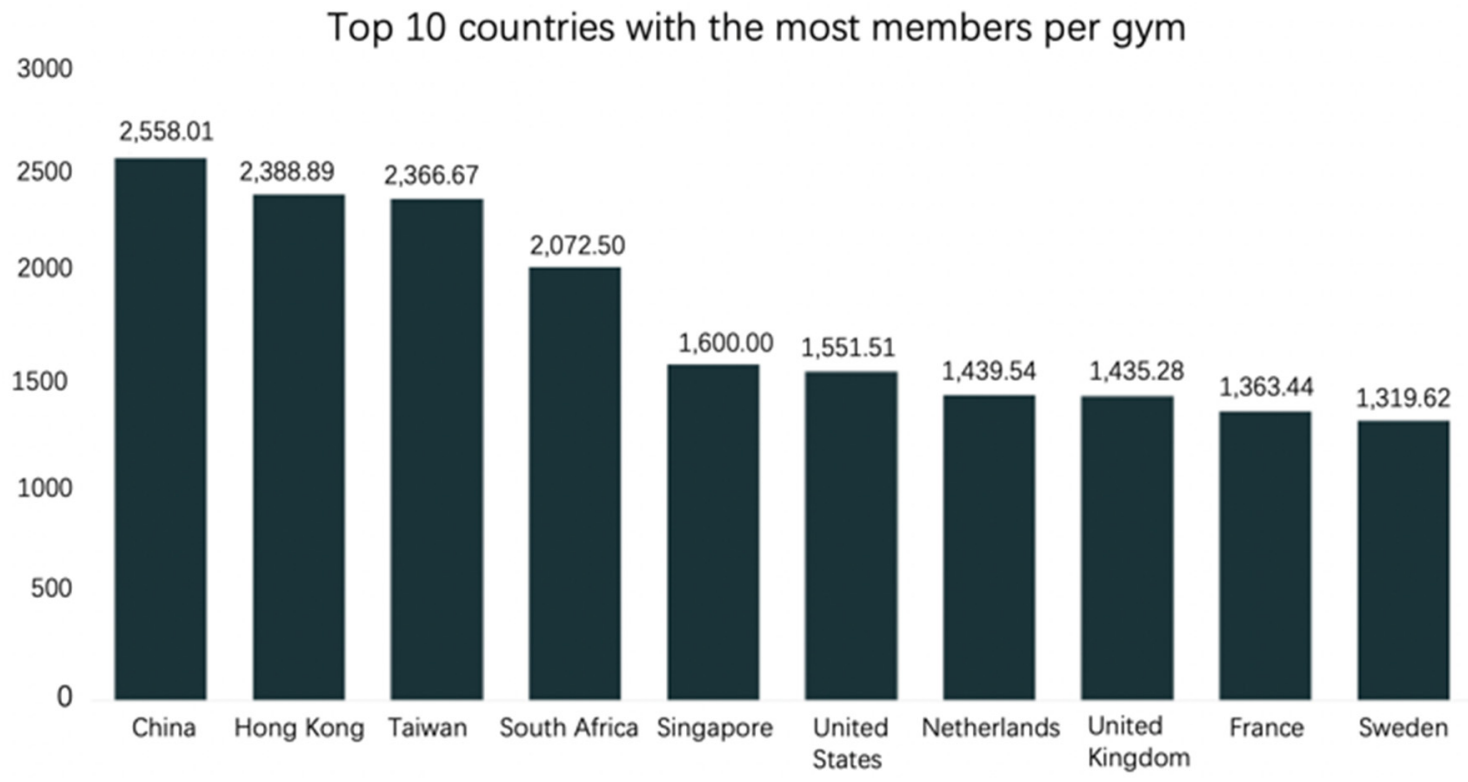

Figure 1. Top 10 countries with the most members per gym [10]

\subsection{Analysis Methods}

\subsubsection{Qualitative SWOT Analysis}

\section{Strengths}

- Health and fitness are paramount to make people appear healthier and happier. A lot of scientific research shows that regular exercise will promote health by preventing several chronic diseases, including cardiovascular disease, diabetes, and cancer (Warburton \& Bredin, 2006). It also shows that regular physical activities can potentially reduce the risk of premature death. Thus, physical fitness is an essential need for humans.

- The company offers a variety of finesses options ranging from Tai Chi, party on bikes, fitness, closing of rings making the health club more appealing to customers.

- The facility is celebrated for building communities and improving health and fitness awareness, hence its tremendous growth. McKinsey's future of wellness survey shows that people care deeply about wellness, in which $79 \%$ of the respondents believe that wellness is important, and $42 \%$ consider it as the top priority. Furthermore, as fitness becomes a new lifestyle, the market size of fitness also increased. Based on the report published by the Ibis World market research, the fitness industry has experienced a $4.4 \%$ annualized growth for the last five years, and this number will keep going up with the usage of fitness apps, fitness influencers and growing health awareness.

\section{Weaknesses}

- Humans are lazy to attend health and fitness clubs. Instead, most of them prefer automated fitness or use pills at the expense of the health clubs. Furthermore, some people prefer screen viewing and living less healthy lifestyles.

- Fitness is considered a hobby, hence a side hustle. This makes it difficult for the consistency of the health club members, especially those who may get distracted along the way.

\section{Opportunities}

- Technology has also created a greater avenue for marketing the health club through various social media and digital platforms, creating newer markets.

- The youthful market is the newest traction to health clubs. Data from Baidu shows that there is a total of $61.7 \%$ of young people (21-30 years old) accounted for the fitness population. This is creating a market for the facility as these groups 
add more numbers to the existing older members of the club.

\section{Threats}

- Increased competition from other health clubs within and without China.

- High costs associated with membership of the health clubs make it difficult for low earning members to join.

\subsubsection{Quantitative Analysis}

The price to earnings $(\mathrm{P} / \mathrm{E})$ ratio is an approach that is used for valuing JianKang Health Club, in which it measures the current share price and the earnings per share (EPS). It is also termed as the price multiple or earnings multiple. The measure is quite helpful for investors as they are able to understand the value of the company with respect to the shares. The higher the ratio, the more expensive a stock is relative to its earning, and vice versa. $\mathrm{P} / \mathrm{E}$ ratio will yield a lower value if EPS rises and the stock price remains the same, lead to a cheaper valuation. In general, a high $\mathrm{P} / \mathrm{E}$ suggests that investors are expecting higher earnings growth in the future compared to companies with a lower P/E. Moreover, the $\mathrm{P} / \mathrm{E}$ ratio can be used to compare two or more companies in the same industry, which help an investor to determine the relative value as an investment. It also aids the company to understand their performance when compared to the past years [7]. In this context, the PE ratio is helpful to JianKang Health Club as the managers can always track the company's value from the past years. While the $\mathrm{P} / \mathrm{E}$ ratio offers a useful valuation, it is worth noting that a lower $\mathrm{P} / \mathrm{E}$ is not always a good thing, as it can also result from a decrease in both stock price and EPS.

$$
\frac{P}{E} \text { ratio }=\frac{\text { Market } \text { Value Share }}{\text { Earnings per share }}
$$

\section{RESULTS AND DISCUSSION}

\subsection{Customers Quantity}

First, we take Chengdu as an example to analyze our target customers. Chengdu is the capital city of Sichuan province, which contains approximately seven million people. Around thirty per cent of people living in Chengdu are adults who have to work for a living. Those adults are under disproportionate pressure. Some of them are just graduated from college; they work more than eight hours a day and more than five days in one week, and the salary they receive is not satisfactory. It takes two to three hours to exercise in the fitness center, which concludes one hour spending on the road and the time waiting for a spot, they do not have enough time, which usually takes two to three hours, to exercise in the fitness center in both weekdays and weekends.
Moreover, current fitness centres implement membership which costs hundreds or thousands depending on location and facility, and it costs an extra hundred for hiring one hour's personal trainer. Most young adults feel the cost to hire personal trainers is unaffordable, and they do not know how to correctly build in shape without personal trainers' instructions. Older adults, ageing between thirty-five and fifty, are usually in a management position after years' hard work, and their spare time lasts only two to three hours, so they also do not have enough time to drive to the fitness center, wait for the equipment and then drive home after exercise. Although their salary increases, hiring personal trainers in the fitness center is also unaffordable for them since they have to raise children and pay for parents' daily costs and, sometimes, medicine costs. For this reason, we know that the current exercise model in the fitness center does not work well for adults between twenty and fifty. Since those are the main target customers for the industry, providing a system that suits their needs which is spending less time and money, will attract them. Our new model, which achieves the goal to decrease the price and the time, will attract most customers.

Our new model achieves the goal by eliminating the middleman in the fitness market. Bosses of fitness center play as the middleman who charges customers three to six hundred for one hour and only give personal trainers thirty to fifty per cent of what customers spend. This is why hiring a personal trainer in the fitness center is expensive and unreasonable. If the middleman no longer exists, personal trainers' salaries will increase, and customers will spend less to enjoy the personal trainer's correct and efficient exercising experience. Thus, current society lacks a platform to connect customers with personal trainers. Luckily, our product can provide a platform for them.

Moreover, people pay more and more attention to their health due to society's pressure and the development of social media. Due to more and more videos and articles in social media teach people the importance of regular exercise, and more examples in daily life warn people consequences of illness, more people exercise in fitness centers four to six times a week, and most of them in fitness center hire personal trainers since incorrect gestures harm body and they do not have enough time to watch videos or read books to learn how to use right gestures to exercise. More and more people want to hire personal trainers when working out. According to a worldwide report which orders different trends customers want to choose in gyms, personal training was no. 9 in 2017 and was no. 8 in 2018 and 2019 out of 25 [8]. Also, in a China survey, the trend to hire personal trainers was ranked no. 17 in 2018 and soared to no. 3 in 2019 [9]. This rapid increase shows a promising market in helping customers find cheap personal trainers through our platform. 
Personal trainers are also willing to use our platform instead of joining the traditional fitness industry. Those in the traditional fitness center have to stay there although they do not have students, and they cannot use their spare time to handle their own business, since the rule is that they have to work full-time and only focus on their work in working hours. Moreover, they earn little in the traditional fitness center since they only earn thirty to fifty per cent of what students pay. In contrast, they earn one hundred per cent of what students pay, and they manage their own time, which means they can do other business or exercise themselves when no student is on schedule if they join our new model of the fitness industry. Therefore, personal trainers will join us since they earn more and have more freedom.

Chengdu contains about two million target customers. China contains about fifty new first-tier cities like Chengdu. These cities have about thirty million target customers in total. Plus, China has four first-tier cities where the population reaches twenty million each. The number of target customers in first-tier cities sums up to twenty million. Thus, the total number of target customers in China is more than fifty million. According to new research, a 2020 report on the global gym industry estimates there are a total of 205,176 gyms in the world [10]. Thus, take an eye on the global market. More than one hundred million people are our target customers.

\subsection{Risks}

One risk our product face is that it is hard to regulate customers and personal trainers. For example, what to do if customers or personal trainers cannot meet in time. One reason that why our product attracts customers is that they can save time, and personal trainers can have more free time. Thus, time is an important factor in our platform, and we need to make strict rules and punishments to regulate both customers and personal trainers to make sure the class begins in time. Another example is that what to do if customers can meet their aiming goal.

Also, the business model faces the risk of losing customer data from cyber criminals who can hack the system. The risk is further compounded by the dynamism of mobile software that needs constant updating and rapid deployment features and functionalities. Competitors might attempt to breach security to access the special features within our mobile platform.

\subsection{Profitability Analysis}

The study predicts that JianKang Health Club will generate profits from the commissions received from the B2B and B2C marketing models. We support the B2B marketing technique for improving business efficiency and reducing unnecessary costs. Thus, the business will pay a flat rate monthly fee also payable on annual or semiannual terms. Additionally, the monthly charges will ensure the maximization of profitability through a market segmentation strategy where customers will be targeted with different services. Market segmentation will help the platform to identify categories of consumers where certain services will target groups that are interested only.

We will evaluate the services that derive the most sales in contrast to those that contribute high margins to facilitate the design of basic, moderate, and VIP packages for its $\mathrm{B} 2 \mathrm{C}$ online customers. Offline customers can also access customized services with different pricing to increase the profitability of the enterprise. For instance, VIP customers will have access to customized services and can enjoy services from other fitness facilities within our mobile app. This category of customers, together with the moderate package subscribers, will use the shuttle services intended to increase the profit margins for the fitness health club. Another revenue channel will be the B2B segment will comprise private coaches sharing training videos on the app.

Through the study, it is obvious that the mobile platform will increase the revenue generated through high value content that is exceedingly instrumental in increasing customer engagement. A high customer engagement rate during their purchase journey is relevant for JianKang Health Club as priceless data will be collected to design future products that are customized. We postulate that keeping the customer is significant in avoiding losses through the abandoned cart. Also, we recommend customer engagement, which they identify as crucial in cultivating an emotional connection with JianKang Health Club. Therefore, keeping them engaged ensures that they make successful purchases and maximize the profit margins.

\section{CONCLUSION}

This article demonstrates a platform, which represents a new business model for the fitness industry to replace the traditional model. In the traditional model, customers can only hire personal trainers through the fitness center, which charges a lot as the middleman and wastes time commuting to the fitness center. Trainers stay in the office the whole day, even when they do not have classes scheduled, and they receive a limited salary. Suppose a product eliminates the existence of the middleman. In that case, it will attract customers and personal trainers to join it instead of continuing to stay in the fitness center, since this product brings benefits to both customers and service providers. In the meantime, the product makes considerable profits as soon as the number of members increases quickly. Since the product's building process is still working, other functions might be added to make it more user-friendly and developed.

Considering the risks of implementing the platform, solutions will be executed correspondingly. The risk 
about the regulation problem might be solved in several methods. A possible way to avoid wasting time is having a late fee, which means it charges them fees counting by minutes when they are late. For example, one-minute late charges ten. A possible solution to ensure customers meet their goals about hiring trainers is that if one customer feels that their trainer is passive about teaching or is inactive during class, they can rate this personal trainer with a low score. Personal trainers who have low scores might not be able to attract new customers. In this way, personal trainers have to try their best to teach students. Also, personal trainers rate customers to avoid abominable customers. If anyone feels that they receive an incorrect rate, they can contain the customer services, and then customer services will investigate through voice record to judge the appropriate score. A possible solution to protect customers' data and ensure privacy requires robust security protocols to prevent unauthorized access to the user and organization's databases. The security procedures will be implemented across the entire network and within the organization's mobile app. As part of the security protocol, establishing a secure connection will require authentication of the endpoint server's identity. One ideal defence is to include TLS/SSL as a security measure in the platform and the transport channel, especially those from third parties. Moreover, the scholars assert that the pinning of certificates for sensitive software, banning of self-signed certificates, and employment of robust cipher suites with relevant industry-standard key lengths can limit security breaches. Our mobile platform will advocate for the application of extra layers to assist in encrypting critical information.

\section{REFERENCES}

[1] Gough, Christina. "Health \& Fitness Clubs Statistics \& Facts." Statista, 10 Mar. 2021, www.statista.com/topics/1141/health-and-fitnessclubs.

[2] "Impact of COVID-19 on Employment Income Advanced Estimates - Statistics Explained.” Impact of COVID-19 on Employment Income - Advanced Estimates, 18 Dec. 2020, ec.europa.eu/Eurostat/statisticsexplained/index.php?title=Impact_of_COVID_19 on_employment_income_-_advanced_estimates.

[3] Indeed Editorial Team. "How Much Do Personal Trainers Make?" Indeed Career Guide, 23 Feb. 2021, www.indeed.com/career-advice/paysalary/how-much-do-personal-trainers-make.

[4] Spraul, Tyler Nasm. "How Many Hours Does a Personal Trainer Work?" Exercise.Com Learn: Your Fitness Business Resource, 25 Aug. 2020, www.exercise.com/learn/how-many-hours-does-apersonal-trainer-work.
[5] Stern, Marc. The Fitness Movement and the Fitness Center Industry, 1960-2000. Business and Economic history, 2008.

[6] ---. “Average Gym Membership Cost 2021 [Gym Price Analysis]." Athletic Shoe Reviews, 6 Aug. 2021, runrepeat.com/gym-membership-cost.

[7] Malmefeldt, E., \& Rao, G. H. (2019). Changing concepts of healthcare: physical activity, fitness, and wellness. EC Endocrinology and Metabolic Research, 4, 238-250.

[8] "WORLDWIDE SURVEY OF FITNESS TRENDS FOR 2020 : ACSM's Health \& Fitness Journal." $L W W, \quad 2020$, journals.lww.com/acsmhealthfitness/Fulltext/2019/11000/worldwide_surv ey_of_fitness_trends_for_2020.6.aspx.

[9] "CHINA SURVEY OF FITNESS TRENDS FOR 2020 : ACSM's Health \& Fitness Journal.” $L W W$, 2020, journals.lww.com/acsmhealthfitness/Fulltext/2019/11000/CHINA_SURV EY_OF_FITNESS_TRENDS_FOR_2020.7.aspx.

[10] Rizzo, Nicholas. "200+ Gym Industry Statistics 2021 [Global Analysis]." Athletic Shoe Reviews, 6 Aug. 2021, runrepeat.com/gym-industry-statistics 